\title{
Bokanmeldelse
}

Jaron Lanier: You Are Not a Gadget: A Manifesto, Knopf, 2010. 209 sider.

Nicholas Carr: The Shallows: What the Internet Is Doing to Our Brains, W.W. Norton \& Co, 2010. 276 sider.

\section{Du er ikke en dings!}

Frykten for at menneskeskapt teknologi skal virke mot menneskenes eget beste, er på ingen måte ny. Teknologiskepsis som fenomen ser faktisk ut til å være like gammelt som teknologien selv. Sokrates, for eksempel, forsøker i Platons dialog Faidros å temperere entusiasme for skrivekunsten ved å hevde at skrift kun er en skygge av det talte ord. Med den egyptiske Totmyten som forelegg forstår Sokrates skrivekunsten som et tegn på forfall; skrift tillater ikke på samme måte som det talte ord at misforståelser kan oppklares, feil rettes opp, sannheten tre frem. I Sokrates' dialektiske higen etter sannheten er skrift en forpurrende teknologi.

Vi som er barn av skrive- og boktrykkerkunstens sivilisasjon, deler neppe Sokrates' motforestillinger, men også i relativ nær fortid ble nye teknologier, blant annet nye medier, møtt med skepsis og frykt. I forrige århundre var man spesielt redd for de såkalte massemediene: film, radio og TV. I våre dager er imidlertid disse gårsdagens medier i ferd med å bli fortært av det store uhyret som er vår tids eneste medium: Internett. Dermed er tiden inne for pamfletter og populærvitenskapelige bøker som stiller spørsmålet: Er Internett dødsstøtet for kultur, sivilisasjon, intelligens, solidaritet, dyp tenkning og alt som for øvrig er bra? Jaron Laniers You Are Not a Gadget: A Manifesto (2010) og Nicholas Carrs The Shallows: What the Internet Is Doing to Our Brains (2010) snuser begge på et «ja».

Før man avviser disse forfatternes utgangspunkt som håpløst bakstreversk, bør man vurdere hvorvidt frykten for nye medier ikke ligner gjetergutten som ropte «Ulv! Ulv!». Bare fordi skrivekunsten og boktrykkerkun- 
sten viste seg å være velsignelser for menneskeheten, betyr ikke det at ethvert nytt medium bringer lignende goder. Hvis det her i tillegg er tale om et medium som - i motsetning til film, radio og TV - gjør at vi bruker mindre tid på å lese, og da bare med dårligere forståelse og utbytte, er det grunn til å tro at ulven faktisk er her denne gangen, og at vår tids gråbein går under det kryptiske navnet $w w w$.

Dataingeniør, musiker og skribent Jaron Lanier var i sin tid en av pionerene bak Virtual Reality, og er for en veteran å regne i Silicon Valley. Han er ikke pessimistisk til hva datateknologi som sådan kan gjøre for menneskeheten, og har heller ingen generell høne å plukke med Internett; isteden angriper han den «strømmen av trivielle designs som noen ganger kalles Web $2.0{ }^{1}$ (58-62) hvis tendens til «fragmentert, upersonlig kommunikasjon har fornedret mellommenneskelig samhandling» (62-66). Lanier frykter at disse mediene vil føre til at en ny generasjon vil vokse opp «med nedsatte forventninger til hva et menneske kan være, til hvem hvert menneske kan bli» (62-66), slik at «vi vil komme til å fremskynde en mørkealder der alt menneskelig er nedvurdert» (1448-1452).

For at denne dystre analysen skal få fotfeste, påpeker Lanier at å utforme informasjonsteknologi er å gi seg i kast med «sosial ingeniørkunst», i den forstand at «ulike medier stimulerer ulike deler av menneskenaturen» (7482). Det programmerere gjør, sier han, er å konstruere forlengelser av den menneskelige væren, og disse forlengelsene blir i sin tur redskaper med hvilke vi forholder oss til andre mennesker og til verden for øvrig. Store forandringer i menneskelig praksis kan dermed skje som et resultat av arbeidet til en liten gruppe teknologiutviklere: «Det kreves kun en liten gruppe ingeniører for å konstruere teknologi som utrolig raskt kan forme den menneskelige erfarings fremtid» (98-102). Om dette kanskje ikke er prinsipielt problematisk, betyr det i hvert fall at teknologiutviklere, i alle ledd, har et ansvar for hva slags medier de bidrar til å realisere. Det betyr at å utforme teknologi, inkludert medieteknologi, er en moralsk relevant aktivitet. Lanier sier det slik: «I en digital verden danner design grunnlaget for etikk» (1138-1148).

Det som først og fremst skremmer Lanier ved Web 2.0, er kombinasjonen av teknologisk lock-in og digital reifisering. Mens førstnevnte betegner hvordan en bestemt teknologi kan legge «låsninger» på fremtidig teknologiutforming, betegner sistnevnte tendensen til at teknologi virker bestemmende på vår sosiale virkelighet. Et eksempel på det første er MIDI, hvor man på tross av videreutvikling fra utgangspunktet ikke har lykkes i å overkomme begrensningene som har ligget i formatet siden opprinnelsen. Laniers eksempel på det siste er hvordan ideen om filen har begynt å organisere vår sosiale virkelighet, på den måten at vi nå forestiller oss at menneskelige uttrykk kommer i «avgrensede stykker som kan organiseres som blader på et abstrakt tre» (228-232). Et tegn på at Web 2.0-konsepter har begynt å 
fungere på samme måte, er ifølge Lanier at folk har begynt å tenke på «vennskap» som noe man først og fremst har på Facebook. Det er selvfølgelig mulig å ha tusenvis av venner på Facebook, sier han, men kun hvis vi nedvurderer betydningen av ordet «venn» (967-971).

Nettopp denne nedvurderingen av mennesker og menneskelig aktivitet er det som opptar Lanier, jf. tittelen. Mens nettet i sin barndom så ut til å være et sted for endeløs kreativitet, der det var få eller ingen føringer på hvordan en webside kunne se ut og brukes, hevder han at «måten Internett har surnet på siden den gang, er virkelig perverst» (251-255). I dag er nettet en i høy grad sentralisert struktur, styrt av mektige selskaper, der individers identitet enten er pseudonymisert og/eller anonymisert, eller, som på Facebook og lignende sider, basert på et skript som kun tilbyr et «standardisert nærvær» (280-284). Med såkalte Web 2.0-designs har vi fått medier som «antyder at en tilfeldig ansamling mennesker utgjør en organisme med et legitimt synspunkt» (74-82). De nye medienes forsvarere begrunner dette ofte med appell til en fremtidig «cloud», «hive mind», eller «noosphere», som man ser for seg vil avføde en superintelligens som vil rettferdiggjøre tapet av individuelle menneskelige evner. Dette vil Lanier ikke høre av: «Noen av kollegene mine mener at en million, eller kanskje en milliard, fragmentariske fornærmelser på sikt vil produsere visdom som overgår et hvilket som helst gjennomtenkt essay». Men, konkluderer han lakonisk: «Søppel inn, søppel ut» (890-894). Vi bør isteden etterstrebe medier som legger til rette for individuell menneskelig intelligens, følsomhet, og kreativitet. Sørger vi ikke for å opprettholde ideen om mennesket som noe annet, og noe viktigere, enn en maskin, vil det hele kunne bli til en selvoppfyllende profeti; vi tenker på mennesker som maskiner, og så blir de, for alle praktiske formål, nettopp det.

Som skribent er Lanier alltid uredd og til tider kreativ, men You Are Not a Gadget skjemmes av formatet. Om boken muligens lever opp til den selvvalgte betegnelsen manifest, fremstår den likevel mest som et litt for raskt sammenvevd lappeteppe av innlegg, kronikker og tidsskriftartikler Lanier har skrevet de siste årene - og slik har da også boken blitt til. Irrelevante ekskursjoner i motsatt retning av bokens tema er det også vel mye av. Det som redder Lanier, er hans øre for treffende overskrifter og slogans, noen av hvilke jeg her gjengir på originalspråket, for full effekt: "You have to be somebody before you can share yourself» (43-48); «The Noosphere is just another name for everyone's inner troll» (823-827); "What happened to musical notes with the arrival of MIDI is happening to people» (1283$1287)$; «At the end of the rainbow of open culture lies an eternal spring of advertisements» (1456-1460).

Hvis You Are Not a Gadget stundom kan anklages for å være like fragmentarisk som webkulturen forfatteren kritiserer, er Nicholas Carrs The Shallows et imponerende stykke populærvitenskapelig arbeid, bare noen få 
bits unna betegnelsen «elegant». Der Lanier lener seg på sin egen lange erfaring fra dataverdenen foruten tallrike referanser av typen «min venn Dave, som jobber i et stort softwareselskap i Silicon Valley, forteller meg at [...]» - støtter Carr seg på et snedig utvalg kilder fra ulike forskningsfelt.

Carrs bok leses best som en Amusing Ourselves to Death for internettalderen, men i motsetning til Neil Postmans klassiker, er The Shallows utstyrt med et hemmelig våpen som gjør den mer uimotsigelig enn nevnte, nemlig «nyere hjerneforskning». Argumentet Carr legger frem, er så enkelt, så strømlinjeformet, at jeg tror ikke det kan være galt: Den menneskelige hjernen er ifølge nyere hjerneforskning kjennetegnet av nevroplastisitet. Det vil si at synapsene i hjernen stadig inngår i nye forbindelser, avhengig av de inntrykkene vi utsetter dem for - hjernen formes med andre ord av de erfaringene vi gjør. Det preger hvilke evner vi mer generelt opparbeider oss som mennesker. Carrs ligning for dette er som følger: «Vi blir, nevrologisk sett, hva vi tenker» (630-634). Han legger imidlertid til at hjernen er noe av en vanejunkie; den etterspør gjerne mer av det vi har gitt den en smakebit av. (Når vi føler en ellers uforklarlig dragning mot å sjekke mailen eller oppdatere status på Facebook, er det altså fordi det rykker i synapsenes internettfot.)

Mediebruk kommer inn i dette bildet omtrent på samme måte som hos Lanier, og for øvrig som hos Marshall McLuhan, nemlig som forlengelser av vår væren. Dette skal $i k k e$ forstås slik at mediene legger seg som et ytre lag - en «andre natur» - på den indre naturen, snarere slik at hjernen tar form direkte som et resultat av hvilke medier vi bruker, og hvordan: «Mediene lar sin magi, eller sin ugang, virke direkte på nervesystemet» (128-133). Forutsetningen for Carrs tese er dermed at mediene, via sin teknologiske utforming, «former hva vi oppfatter og hvordan vi oppfatter det - og, om vi bruker dem nok, forandrer de hvem vi er, som individer og som samfunn» (124-128). I en interessant gjennomgang viser Carr hvordan slike endringer har funnet sted historisk: Klokker skapte «klokketid» og nye sosiale omgangsformer, kart skapte en ny rom- og verdensforståelse, og skrivemaskiner skapte et nytt forhold til skriving, for ikke å nevne nye skribenter. Men den viktigste teknologien i denne, altså vår, historie er likevel boktrykkerkunsten.

Carr hevder at vi i øyeblikket er i ferd med å la oss forandre av vår egen internettbruk på en slik måte og i et slikt omfang at mediet og kulturen som skapte den moderne vestlige sivilisasjon - henholdsvis boken og dens «intellektuelle etikk» - er i ferd med å bli avleggs. I sin tid formet boklesing hjernen slik at den ble kapabel til noe som ikke i utgangspunktet er spesielt nærliggende for mennesker, nemlig vedvarende og dyptloddende konsentrasjon. Boklesing krever stor grad av mental disiplin, påpeker Carr; det krever rettet konsentrasjon over lang tid, en «uavbrutt oppmerksomhet mot et enkelt, statisk objekt» (1122-1126). Dette er noe unikt i menneskehetens 
historie, for vår normale tilstand - slik som hos mange andre dyrearter - er et flakkende og lett distrahert blikk. Imidlertid lykkes det boken, og spesielt den innvevingen av boken i folks dagligliv som fulgte av Gutenbergs oppfinnelse, å skape et slikt dybdemenneske. Helt siden Gutenberg har dermed «det lineære, litterære sinnet vært sentralt for kunst, vitenskap og samfunn» - det var bokhjernens sinn som skapte renessansens fantasi, opplysningstidens rasjonalitet, den industrielle revolusjons oppfinnsomhet og modernismens omveltningstrang - men «snart kan $\operatorname{det}[$ te] være gårsdagens sinn» (246-250). I dag befinner vi oss, ifølge Carr, mellom to teknologiske verdener: «Etter 550 år er boktrykkerkunsten og dens produkter i ferd med å fortrenges fra sentrum til ytterkantene av vårt intellektuelle liv» (1350-1355).

Carr gir et treffende bilde på hva denne overgangen innebærer: «En gang var jeg en dypvannsdykker i et hav av ord. Nå suser jeg av gårde på overflaten som en fyr på vannscooter» (180-184). Internett graver altså ikke bare bokens grav, men også - noe som er verre - bokmenneskets, det vil si bokhjernens, grav. Som erstatning for trykkpressens dybdemennesker får vi nettsamfunnets «kroniske vimsehoder» (184-187), som med sine «sjonglørhjerner» (1972-1976) ikke er i stand til annet enn «stakkato tenking» (192-196).

Carr ser Internett som en eneste stor forstyrrelsesmekanisme, en maskin som «fanger oppmerksomheten bare for å spre den» (2025-2029). Internett fremmer altså et handlings- og oppmerksomhetsmønster som er mer typisk for andre dyr, nemlig en overflateoppmerksomhet hvor man hele tiden er åpen for bredden av inntrykk, men hvor man ikke makter å gå i dybden på noen av dem. Det Carr frykter, er at det «rolige, fokuserte, uforstyrrede, lineære sinnet er i ferd med å bli skjøvet til side av en ny type sinn som ønsker og trenger å ta inn og spy ut informasjon i korte, usammenhengende, ofte overlappende salver - jo raskere, jo bedre» (238-241).

Naturligvis kan man kjøpe Carrs argument om en overgang fra bokhjerner til skjermhjerner, men samtidig benekte at det er spesielt bekymringsverdig. Kanskje kan lettdistraherte vimsehoder være vel så nyttige som sneversynte konsentrasjonsfreaks? Vel, Carr har et svar også til denne innvendingen. For mens boklesing fremmet en type hjerneaktivitet der inntrykk ble omgjort til «skjemaer», altså mer eller mindre varige forståelsesrammer for fremtidige inntrykk, gjør nettbruk at informasjon følger den velkjente banen inn-det-ene-øret-og-ut-det-andre. Nettbruk vanskeliggjør altså progressiv læring. Evnen til å lære nye ting avhenger nemlig sterkt av «working memory load», altså mengden inntrykk vi ber hjernen sortere i enhver situasjon, og det nettet gjør - med sitt masseinformasjonsangrep på hjernene våre - er å fylle opp arbeidsminnet. Dermed blir det vanskeligere å skille relevant fra irrelevant informasjon, og resultatet er ifølge Carr at «vi blir tankeløse forbrukere av 'data'» (2149-2153). I en slik tilstand «makter vi ikke å oversette ny informasjon til skjemaer. Evnen til å lære blir lidende, 
og forståelsen forblir overflatisk» (2141-2149). Sagt med litt mindre finfølelse enn Carr legger for dagen: Netthjerner er dumme.

Carr lar ikke denne konklusjonen bli stående som en løs hypotese, men understøtter argumentasjonen ved å vise til en rekke empiriske studier. På visse områder synes forskningsresultatene ganske entydige; for eksempel bringer han overbevisende dokumentasjon på at evnen til å forstå, huske og anvende informasjon er konsekvent lavere for tekst man har lest på skjerm, enn for tekst man har lest på papir, og videre, at folk som leser mye på skjerm, får disse evnene svekket selv når de leser på papir.

Styrken ved The Shallows er nettopp at forfatteren så finurlig understøtter sine slagkraftige mcluhaneske kulturteorier med oppdatert hjerneforskning, og at han med dette som utgangspunkt dokumenterer med empiri hvilket utslag internettbruk får på både individnivå og samfunnsnivå. Som Carr sier selv, utgjør nevroplastisitet «the missing link for å forstå hvordan informasjonsmedier og andre intellektuelle teknologier har utøvd innflytelse over sivilisasjonen og, på et biologisk nivå, styrt den menneskelige bevissthetens historie» (866-874). Siden Internett fortsatt er et ungt medium, ser Carr riktignok ikke mer enn omrisset av hvordan det kommer til å styre den menneskelige bevissthet. Men om dette omrisset er noe i nærheten av hva fremtiden vil bringe, bør varselbjeller begynne å ringe.

Til slutt kan jeg opplyse om at de ukonvensjonelle sidehenvisningene $i$ denne teksten skyldes at jeg har lest begge bøker i digital versjon, med hjelp av hva Lanier ville kalt en «dings». Såpass overbevisende var bøkene imidlertid at jeg må konkludere slik: Neppe igjen.

Anmeldt av Kristian Bjørkdahl, Etikkprogrammet / Senter for utvikling og miljø (SUM) ved Universitetet $i$ Oslo

\section{Note}

1 Av hensyn til leseligheten har jeg oversatt de fleste av sitatene fra originalspråket. 